Slavica

bruxellensia

\section{Slavica bruxellensia}

Revue polyphonique de littérature, culture et histoire

slaves

$10 \mid 2014$

Espace slave, espace germanique

\title{
Benjamin Goriély (1898-1986), un médiateur privilégié de la littérature russe
}

\section{Svetlana Cecovic et Hubert Roland}

\section{OpenEdition}

\section{Journals}

Édition électronique

URL : https://journals.openedition.org/slavica/1655

DOI : 10.4000/slavica.1655

ISSN : 2034-6395

\section{Éditeur}

Université libre de Bruxelles - ULB

\section{Référence électronique}

Svetlana Cecovic et Hubert Roland, «Benjamin Goriély (1898-1986), un médiateur privilégié de la littérature russe », Slavica bruxellensia [En ligne], 10 | 2014, mis en ligne le 15 avril 2014, consulté le 21 septembre 2021. URL : http://journals.openedition.org/slavica/1655 ; DOI : https://doi.org/10.4000/ slavica. 1655

Ce document a été généré automatiquement le 21 septembre 2021.

\section{cc) $(1) \ominus$}

Les contenus de Slavica bruxellensia sont mis à disposition selon les termes de la Licence Creative Commons Attribution - Pas d'Utilisation Commerciale - Pas de Modification 3.0 France. 


\title{
Benjamin Goriély (1898-1986), un médiateur privilégié de la littérature russe
}

\author{
Svetlana Cecovic et Hubert Roland
}

1 Le champ d'étude des médiateurs culturels en Europe est en pleine expansion et nourrit actuellement plusieurs projets de recherche et de publications, attirant l'attention sur des personnalités mal connues, mais dont l'œuvre de traduction et de médiation a - sans qu'on en prenne réellement conscience - très largement façonné notre perception des cultures et littératures étrangères ${ }^{1}$. Au-delà d'un intérêt biographique pour des parcours dignes d'intérêt sur le plan de l'étude des échanges culturels internationaux, les études sur les médiateurs drainent avec elles des questions méthodologiques qui apportent un renouvellement certain aux sciences humaines et sociales. Les médiateurs se situent à la croisée des transferts culturels, de l'historiographie et de l'histoire sociale de la littérature, mais aussi de l'imagologie comparée et de l'étude des réseaux politiques et intellectuels - notamment par le biais des revues culturelles et littéraires. Dans le cadre d'un projet de recherche actuellement mené à l'Université catholique de Louvain, portant sur la réception de la littérature russe et les images de la Russie en Belgique dans la période de l'entre-deux guerres ${ }^{2}$, notre attention a inévitablement été attirée par la figure de Benjamin Goriély (1898-1986), traducteur, publiciste et médiateur de la culture russe.

Goriély est né le 22 août 1898 à Varsovie. Il fut étudiant à Kharkov, avant que la révolution ne le mène en 1918 à Moscou, où il prit une part active aux événements révolutionnaires et se porta volontaire pour l'Armée rouge ${ }^{3}$. Comme la situation politique tourna mal, il quitta l'armée et rejoignit un temps la Pologne, qu'il quitta alors pour partir étudier à Berlin. Attiré par la culture francophone, Goriély décida en 1921 de s'installer à Bruxelles, une capitale francophone qu'il situait dans le sillage immédiat de Paris. Lorsqu'il quitta Bruxelles pour gagner Paris en 1930, Goriély avait déjà entamé une activité importante de médiateur qu'il poursuivit pratiquement jusqu'à la fin de sa vie. Son œuvre d'écrivain et critique, de traducteur et de journaliste en fit un médiateur franco-russe de premier plan. Passeur et introducteur de Vladimir Vladimirovič 
Majakovskij, Boris Leonidovič Pasternak, Viktor Vladimorovič Khlebnikov, il fut aussi l'éditeur de la correspondance de Lev Nikolaevič Tolstoj. Sa médiation de la littérature russe englobe donc aussi bien les auteurs « classiques » du XIX siècle que des poètes plus tardifs et des avant-gardes, pour lesquels il joua un rôle plus novateur de découvreur, sans oublier son intérêt pour les écrivains soviétiques. Il décéda à Paris en 1986.

Bien des détails de la vie de Goriély avant et pendant son séjour en Belgique nous sont connus grâce au manuscrit de ses souvenirs Nul ne reconnaitra les siens ${ }^{4}$. Si la lecture de ceux-ci, rédigés après la Deuxième Guerre mondiale, appelle bien sûr une lecture critique, ils expliquent toutefois une dimension importante de son activité de médiateur par l'impulsion nouvelle qu'il donna à l'histoire culturelle et littéraire. Dans la continuité des années révolutionnaires à Moscou qui l'avaient tant marqué, Goriély consacra sa vie à une réflexion sur le phénomène de la poésie révolutionnaire et à son impact sur l'avenir littéraire de la Russie et de l'Europe. Il joua donc un rôle crucial dans l'interprétation de la poésie de l'avant-garde russe en Occident, ainsi que dans la genèse de la littérature prolétarienne en Belgique par le biais d'un modèle «russe». Cette idée de poésie révolutionnaire, Goriély l'imagine fort logiquement au niveau international. À cet égard, la position géographique de la Belgique, entre la France et l'Allemagne, se révèle stratégiquement très favorable ; elle favorise des échanges et transferts triangulaires, qui organisent des convergences en réseau.

4 L'existence nomade du jeune Goriély l'avait mené entre ses séjours en Russie et en Belgique, dans le Berlin des débuts de la République de Weimar. Observant de près l'agitation révolutionnaire en Allemagne et le climat de répression qui s'y opposait, il s'y était intéressé au phénomène de l'expressionnisme, qui « atteignait son apogée. Il voulait la mort des pères, des maitres à penser, du rationalisme. L'expression[n]isme glorifiait l'absolu, c'est-à-dire la mort » ${ }^{5}$. Dès ce moment, on constate l'intérêt soutenu de Goriély pour les courants d'avant-garde "jeunes", ceux qui ont entrepris de détruire et régénérer l'Europe littéraire "bourgeoise ». On constate donc ici un trait transversal de son action de médiateur, et une tendance majeure de son œuvre d'historiographe des mouvements d'avant-garde. Dans un article consacré aux « littératures de transition », qu'il donna pour la revue belge Tentations, Goriély resitua l'importance de ces mouvements littéraires du premier quart $\mathrm{du} \mathrm{xx}^{\mathrm{e}}$ siècle (futurisme, cubisme, dadaïsme, expressionnisme) qui, selon lui, « contribuèrent à la destruction de l'ancienne littérature bourgeoise (...) [et] déblayèrent le terrain pour laisser place à l'épanouissement d'une littérature constructive, prolétarienne ${ }^{6}$, dans laquelle la Russie nouvelle se devait de donner le ton.

5 Les étapes du parcours de Goriély en Belgique illustrent bien la manière dont il fit son entrée dans le champ intellectuel de la médiation. Dès son arrivée à Bruxelles, il s'inscrivit à la faculté de Sciences Naturelles de l'Université Libre de Bruxelles mais son activisme politique prit rapidement le pas sur ses études à proprement parler et c'est ainsi qu'il s'engagea toujours davantage comme jeune journaliste et publiciste. Après avoir publié ses souvenirs de la révolution russe sous le pseudonyme de Maximof dans le périodique étudiant L'Universitaire, il multiplia les activités de diffusion de la littérature russe, dans une perspective essentiellement sociale. Ainsi présenta-t-il un exposé sur Anna Karénine de Tolstoj, puis un autre sur la poésie soviétique, à Charleroi dans un « club de la culture ». Son public rassemblait principalement des ouvriers émigrés, polonais, russes, juifs. En réalité, Goriély fréquenta les milieux du futur parti communiste. Par le biais de liens personnels avec les acteurs principaux de la littérature prolétarienne en 
Belgique comme Augustin Habaru, Pierre Hubermont et Albert Ayguesparse ${ }^{7}$, il fut progressivement introduit comme chroniqueur culturel du quotidien communiste Le Drapeau Rouge, puis noua des contacts avec des revues comme La Lanterne sourde, Le Rouge et le noir et même Sept Arts. Mais c'est surtout dans l'expérience de Tentatives, une revue éphémère, à laquelle succéda un temps Prospections avant de disparaître, que Goriély fut pleinement intégré. Il y fit la connaissance de Charles Plisnier, mais aussi de René Baert, avec qui il rédigea par la suite une anthologie de la poésie russe sous le titre La Poésie nouvelle en URSS (1928) ainsi que la première traduction en français du célèbre poème Oblako v štanakh(Le Nuage en pantalon)de Majakovskij(1930) ${ }^{8}$.

6 Le mérite principal qu'on reconnut à Goriély fut lié à son aura de témoin d'un événement majeur, dont on parla beaucoup à l'époque - la révolution d'Octobre de 1917-1918. Celle-ci devint pour lui l'inspiration principale de la création littéraire autour des futuristes comme Majakovskij et Khlebnikov ou encore David Davidovič Burljuk et Aleksej Eliseevič Kručenykh qu'il croisa dans le fameux café des futuristes de la Anastasevskij Pereulok à Moscou' $^{9}$. Certes, Goriély fut loin d'être le seul à parler de la révolution russe et cet événement fut l'objet des souvenirs personnels d'un certain nombre de publicistes et médiateurs de la culture russe en Belgique comme Jules Destrée, Marcel Thiry ou Zinaïda Schakovskoy. Les discours sur la révolution renforcèrent une image déjà existante de la Russie communiste, qui avait permis aux milieux bourgeois de définir le socialisme comme quelque chose d'oriental, ou bien de non-européen ${ }^{10}$. Le but de Goriély était en revanche de contribuer par ses travaux à la désintégration de la culture bourgeoise. D'après lui, les mouvements de l'avant-garde russe, rassemblés sous le nom de futurisme suite à l'influence grandissante de Filippo Tomasso Marinetti, représentaient en réalité une littérature de transition en marche vers la littérature prolétarienne, comme on l'a vu. Ce projet n'a pas tout à fait réussi en Belgique surtout parce que le mouvement fut, d'après Goriély, pénétré par de nombreux courants caractéristiques d'un "nouveau romantisme $»^{11}$, qui orienta certains membres du mouvement vers le catholicisme (Plisnier) ou bien vers le nazisme (Baert).

7 Goriély contribua finalement à un discours sur la "mystique révolutionnaire " - soustitre emprunté à son étude sur la poésie dans la révolution russe- discours très répandu dans le monde intellectuel belge et occidental. Il parle du danger du «bateau ivre » au sein du mouvement prolétarien mais d'un autre côté, il admire les poètes dans la révolution russe, évoquant «la musique des mots, l'alcool brûlant de la forme qui charmaient cette foule venue de toutes les classes et de tous les coins de la Russie ${ }^{12}$. Tout particulièrement, il admire Aleksandr Aleksandrovič Blok qui sut, d'après lui, le mieux comprendre la Révolution et achever un équilibre entre éléments politiques et littéraires ${ }^{13}$.

8 Sur le plan de la médiation de la littérature expressionniste allemande, on remarquera pour finir que Goriély fut, indirectement, à l'origine de la réception de l'écrivain Carl Sternheim en Belgique et dans la francophonie. Ayant lu un article à son propos dans le journal russe prosoviétique de Berlin RuL', il recommanda Sternheim à son épouse Hélène Temerson-Goriély ${ }^{14}$, qui s'était entre-temps inscrite comme étudiante en philologie germanique à l'Université Libre de Bruxelles et consacra à l'auteur allemand un travail de recherche. Cet intérêt trouva plus tard un prolongement via quelques traductions de Sternheim, publiées en Belgique dans les années 1930. C'est sans aucun doute la critique décapante de la bourgeoisie dans les pièces de Sternheim qui attira l'attention de Goriély, 
y décelant là aussi une œuvre qui alimentait son propos de la nécessité d'une littérature nouvelle et révolutionnaire en Europe ${ }^{15}$.

\section{NOTES}

1. Voir le colloque qui se tiendra à l'Université Catholique de Leuven (KU Leuven, Belgique), du 5 au 7 juin 2014 : http://www.arts.kuleuven.be/cetra/cm/home (consulté le 7 avril 2014) et le numéro 45/2014 de Textyles. Revue des lettres belges de langue française consacré au thème des «Passeurs. Médiation et traduction en Belgique francophone» (éd. par Béghin L. \& Roland H.). Hubert Roland a consacré un article de ce numéro aux années belges de Benjamin Goriély (1921-1930).

2. Ce projet a déjà mené l'organisation, à l'Université Catholique de Louvain (Louvain-la-Neuve, Belgique) les 10 et 11 février 2015, du colloque intitulé «Réception, transferts, images: Phénomènes de circulation littéraire entre la Belgique, la France et la Russie 1870-1940», dont la matière mènera à une publication en 2015 chez l'éditeur P.I.E.-Peter Lang (coll. « Comparatisme et société »). Il sert également de cadre à la thèse de Svetlana Cecovic, en cours de rédaction.

3. C'est du moins le récit qu'il fit de son parcours dans une revue dirigée par des étudiants belges de gauche : Cf. Goriély B., « Souvenirs de la révolution russe », in : L'Universitaire, 24 mars 1925.

4. Ce tapuscrit est conservé, avec l'ensemble de ses archives, à la Bibliothèque de l'Alliance israélite universelle, Paris, AP 21/5. Nous remercions Serge Goriély d'en avoir mis une copie à notre disposition.

5. Nul ne reconnaîtra..., Ibid., p. 167.

6. Cf. Goriély B., «Littérature de transition », in : Tentatives, février/mars 1929, pp. 13-15.

7. Cf. Aron P., La littérature prolétarienneen Belgique francophone depuis 1900, Labor, Bruxelles, 1995, pp. 53-78 \& 109-172.

8. Marina Cvetaeva fut une des premières traductrices de Vladimir Vl. Majakovskij en français. Ses traductions ont été souvent très critiquées. Elle a traduit quelques poèmes, mais à notre connaissance, pas Oblako $v$ Štanakh (Le Nuage en pantalon). À son sujet, voir Coudenys W." "Te poslednie vy mozhete ispravljaŤ c točki zrenija stilistiki": četyre zabytykh francuzskikh perevoda Mariny Cvetaevoj » (Vous pouvez corriger ces derniers du point de vue de la stylistique : quatre traductions françaises oubliées de Marina Cvetaeva), in: Revue des études slaves, t. LXVI, fascicule 2, 1994. pp. 401-411. Une analyse de la traduction de Goriély, très intéressante du point de vue stylistique, reste à faire.

9. Goriély B., Les poètes dans la révolution russe, Gallimard, Paris, 1934, p. 67.

10. Cf. Adamovsky E., « Russia as the Land of Communism in XIX ${ }^{\text {th }}$ Century? Images of Tsarist Russia as a Communist Society in France, c. 1840-1880 " (La Russie comme pays du communisme au XIX ${ }^{\mathrm{e}}$ siècle ? Images de la Russie tsariste comme société communiste aux yeux des Français), in : Cahiers du Monde russe, vol. 45, $\mathrm{n}^{\circ}$ 3-4, 2004, p. 514.

11. Bengor G. [pseudonyme de Goriély], «Le nouveau romantisme », in: Tentatives, juin-juillet 1928, p. 21.

12. Goriély B., Les poètes dans la révolution russe, op. cit., p. 41.

13. Ibid., p. 44.

14. Goriély et Hélène Temerson se séparèrent lors du départ du premier à Paris. Leur fils, Georges (1921-1998), fit carrière comme professeur de philosophie politique à l'Université Libre 
de Bruxelles. Leur petit-fils Serge (né en 1963) vit comme auteur-dramaturge et enseignantchercheur à Bruxelles.

15. Ceci au risque de trahir la pensée d'un auteur comme Carl Sternheim, qui n'était pas, pour sa part, un adepte de la révolution.

\section{RÉSUMÉS}

Benjamin Goriély, traducteur et publiciste, a joué un rôle important dans la médiation de la pensée russe en Belgique dans l'entre-deux-guerres, en particulier entre 1925 et 1930. Grâce à son séjour à Moscou pendant la révolution de 1917 et à Berlin par la suite, il devint un acteur important des rapports triangulaires Belgique-Allemagne-Russie. Sa collaboration avec le périodique étudiant L'Universitaire et les acteurs principaux du mouvement prolétarien belge comme Augustin Habaru, Pierre Hubermont, Charles Plisnier et Albert Ayguesparse lui permettent d'accéder au Drapeau Rouge, le quotidien communiste, ainsi qu'aux revues importantes (quoique éphémères) comme Prospections et Tentatives. Progressivement, Goriély devient un des pionniers de la littérature prolétarienne en Belgique autour d'un modèle soviétique. Le futurisme russe qui occupe une place privilégiée dans le travail de ce médiateur, il le considère comme un mouvement transitoire vers la littérature prolétarienne. À part ses travaux sur la littérature et la révolution russes, Goriély suivait attentivement la littérature allemande et inspira son épouse Hélène Temerson-Goriély, pour qu'elle consacre, à l'Université Libre de Bruxelles, une première thèse de doctorat qui porta sur Carl Sternheim, l'écrivain expressionniste allemand. Son interprétation précieuse $\mathrm{du}$ futurisme russe et des expressionnistes allemands exprime la nécessité d'une littérature entièrement nouvelle et révolutionnaire. Malgré son départ définitif à Paris en 1930, suite à la mauvaise fortune du mouvement prolétarien en Belgique, le travail de Goriély a largement contribué à un éclairage unique du phénomène de la « poésie révolutionnaire ».

\section{INDEX}

Mots-clés : expressionnisme allemand, futurisme russe, littérature prolétarienne, médiation, traduction

Index géographique : Allemagne, Belgique, France, Russie

Index chronologique : entre-deux-guerres

Keywords : german expressionism, mediation, proletarian literature, russian futurism, translation

\section{AUTEURS}

\section{SVETLANA CECOVIC}

UCLsvetlana.cecovic@uclouvain.be 
HUBERT ROLAND

F.R.S./FNRS-UCL hubert.roland@uclouvain.be 